\title{
Windows 8: What Educators Need to Know
}

\author{
Richard G. Vedder \\ Department of Information Technology and Decision Sciences, \\ University of North Texas, Denton, TX, USA
}

\author{
vedder@unt.edu \\ Executive Summary
}

In October 2012, Microsoft will release the commercial version of its next operating system, presently called "Windows 8 ." This version represents a significant departure from the past. Microsoft wants this operating system to meet user needs regardless of physical platform (e.g., desktop, notebook, tablet, mobile phone). As part of this mission, the company has created a new, touch-oriented user interface that has already appeared on new Windows phones. What will the release of this new operating system, which does not rely on mouse-clicks, mean for educators? How will the Windows 8 interface challenge teachers of information technology? This article will discuss these issues based on what is currently known about this new product. Schools do not need to upgrade, as there is no "killer application" forcing the use of Windows 8. Current Windows 7 software will run fine on most versions of Windows 8. Using a touch-screen display with Windows 8 is helpful, but not required.

Keywords: Windows 8, touch-screen interface, smart tiles, start orb, start button, tablet PC

\section{Introduction}

Microsoft's next version of its flagship product, Windows 8, represents a major departure from earlier versions with respect to the user interface and general behavior. The differences are so pronounced that its eventual impact on consumers could be as profound as that of Windows 95, which stimulated end-user migration from command-line software to windowing software. In association with its release, Windows 8 will appear on new desktop, notebook, and tablet PCs, which in turn means that some students will bring their Windows 8 computers into the classroom late this year. What do IT educators need to know about Windows 8 so that they can prepare for this event?

\section{Characteristics of the Windows 8 Operating System}

\section{Hardware Requirements}

Material published as part of this publication, either on-line or in print, is copyrighted by the Informing Science Institute. Permission to make digital or paper copy of part or all of these works for personal or classroom use is granted without fee provided that the copies are not made or distributed for profit or commercial advantage AND that copies 1) bear this notice in full and 2) give the full citation on the first page. It is permissible to abstract these works so long as credit is given. To copy in all other cases or to republish or to post on a server or to redistribute to lists requires specific permission and payment of a fee. Contact Publisher@InformingScience.org to request redistribution permission.
Can your PC or your school's current equipment run Windows 8? Basically, if a computer can run Windows 7 , it can run Windows 8. However, for decent performance the computer needs at least a dual-core CPU, a dedicated graphics processor (CPU), and $2 \mathrm{~GB}$ of RAM for running 32-bit software (double that for 64-bit programs). Your computer does not have to use a solid-state drive (SSD); traditional hard drives are fine. 
In either format, do not settle for a drive with less than $128 \mathrm{~GB}$ capacity, which will (for example) store Windows 8 with some apps, Office 2010 Professional, and Visual Studio 2010.

The same situation applies to notebooks, with an important caveat. Screen resolution will be a deal breaker for any notebook that cannot support a screen resolution of $1024 \times 768$ (1366x768 for advanced features) - and that covers a lot of currently available notebook machines.

Although the Windows 8 interface is designed for touch-screen use, it responds well to mouse and keyboard input. If you have large fingers, you will probably need to use a mouse or stylus. Likewise, if you need to do a lot of typing, you may find a traditional keyboard easier to use than the on-screen versions (which include a keyboard optimized for texting and a slit keyboard design for those who prefer typing with their thumbs.)

The author installed Windows 8 on a Samsung Series 7 Slate PC and has used it satisfactorily in class (http://www.samsung.com/us/computer/tablet-pcs/XE700T1A-A03US). As purchased, the Samsung Slate PC came with a 128 GB SSD, wireless keyboard, stylus, and docking station. Although the supplied wireless keyboard works fine, the author found it hard to use in darkened classrooms. To solve this problem, the author bought a Logitech Wireless Illuminated Keyboard K800 (http://www.logitech.com/en-us/keyboards/keyboards/wireless-illuminated-keyboardk800). Moreover, since this tablet ships with only mini-HDMI and USB outputs, the author also purchased a UGA-165 video adapter to connect the Slate PC with both monitors and classroom video ports (http://plugable.com/products/uga-165/).

\section{Versions of the Operating System}

As of the time of writing, Microsoft will offer four versions (see Table 1) of Windows 8: Home, Professional, Enterprise, and Windows RT ("Run Time"). The first three will offer an upgrade/migration path from Windows 7. Professional and Enterprise will include additional security features such as encryption and remote computer access via a virtual private network.

Windows RT is very different and owes its existence to the explosive growth of the energyefficient ARM CPUs in all sorts of mobile devices, including phones, many tablets, digital media players, and game players. Windows RT will run only on ARM devices; it will not run on any computer using an Intel/AMD processor. An important consequence of this is that Windows RT will not run any traditional Windows software. It will only host applications specifically written for it, such as a special version of Microsoft Office 2013.

\begin{tabular}{|l|c|c|c|c|}
\hline \multicolumn{5}{|c|}{ Table 1: Sample Features Across All Versions of Windows 8 } \\
\hline \multicolumn{1}{|c|}{ FEATURE } & $\begin{array}{c}\text { WINDOWS 8 } \\
\text { (HOME) }\end{array}$ & $\begin{array}{c}\text { WINDOWS } \\
\mathbf{8} \text { PRO }\end{array}$ & $\begin{array}{c}\text { WINDOWS 8 } \\
\text { ENTERPRISE }\end{array}$ & $\begin{array}{c}\text { WINDOWS } \\
\text { RT }\end{array}$ \\
\hline CPU Architecture & $\begin{array}{c}\text { Intel/AMD } \\
(\mathrm{x} 86 / 64)\end{array}$ & $\begin{array}{c}\text { Intel/AMD } \\
(\mathrm{x} 86 / 64)\end{array}$ & $\begin{array}{c}\text { Intel/AMD } \\
(\mathrm{x} 86 / 64)\end{array}$ & ARM \\
\hline Upgrades from Windows 7 Home & YES & YES & --- & --- \\
\hline Upgrades from Windows 7 Pro or Ultimate & --- & YES & YES & --- \\
\hline Win 8 interface (start screen, live tiles, etc.) & YES & YES & YES & YES \\
\hline Includes “Windows 7+” & YES & YES & YES & --- \\
\hline Accesses Windows Store & YES & YES & YES & YES \\
\hline Supports Office 2012 & YES & YES & YES & --- \\
\hline Supports Office 2013 (beta) & YES & YES & YES & YES \\
\hline
\end{tabular}




\begin{tabular}{|l|c|c|c|c|}
\hline Supports Internet Explorer 10 & YES & YES & YES & YES \\
\hline Supports Windows Media Player & YES & YES & YES & --- \\
\hline File/folder encryption & --- & YES & YES & --- \\
\hline Whole device encryption & --- & --- & --- & YES \\
\hline Supports traditional 32-/64-bit software & YES & YES & YES & --- \\
\hline
\end{tabular}

\section{Past and Future Interfaces}

Microsoft has designed Windows 8 as a bridge between a mouse-keyboard past and a touch future. Consequently, the operating system offers two very different interfaces. To support traditional "legacy" Windows software, most versions offer an improved Windows 7, that the author will call Windows "7+." It provides the standard Windows desktop experience, except that the Start Orb with its associated menu is completely absent - Microsoft wants you to access your programs using the Windows 8 Start Menu, which occupies the entire screen (Figure 1). This design decision has raised howls of protest, and third-parties are already creating substitute Start Buttons. Currently, a good alternative is Power 8 (https://code.google.com/p/power8/). Another noteworthy improvement is a remodeled Windows Explorer, which now sports its own ribbon of frequently used tasks across the top of its screen. Windows $7+$ also supports touch but, unless you have small fingers, you will be using a mouse or stylus heavily.

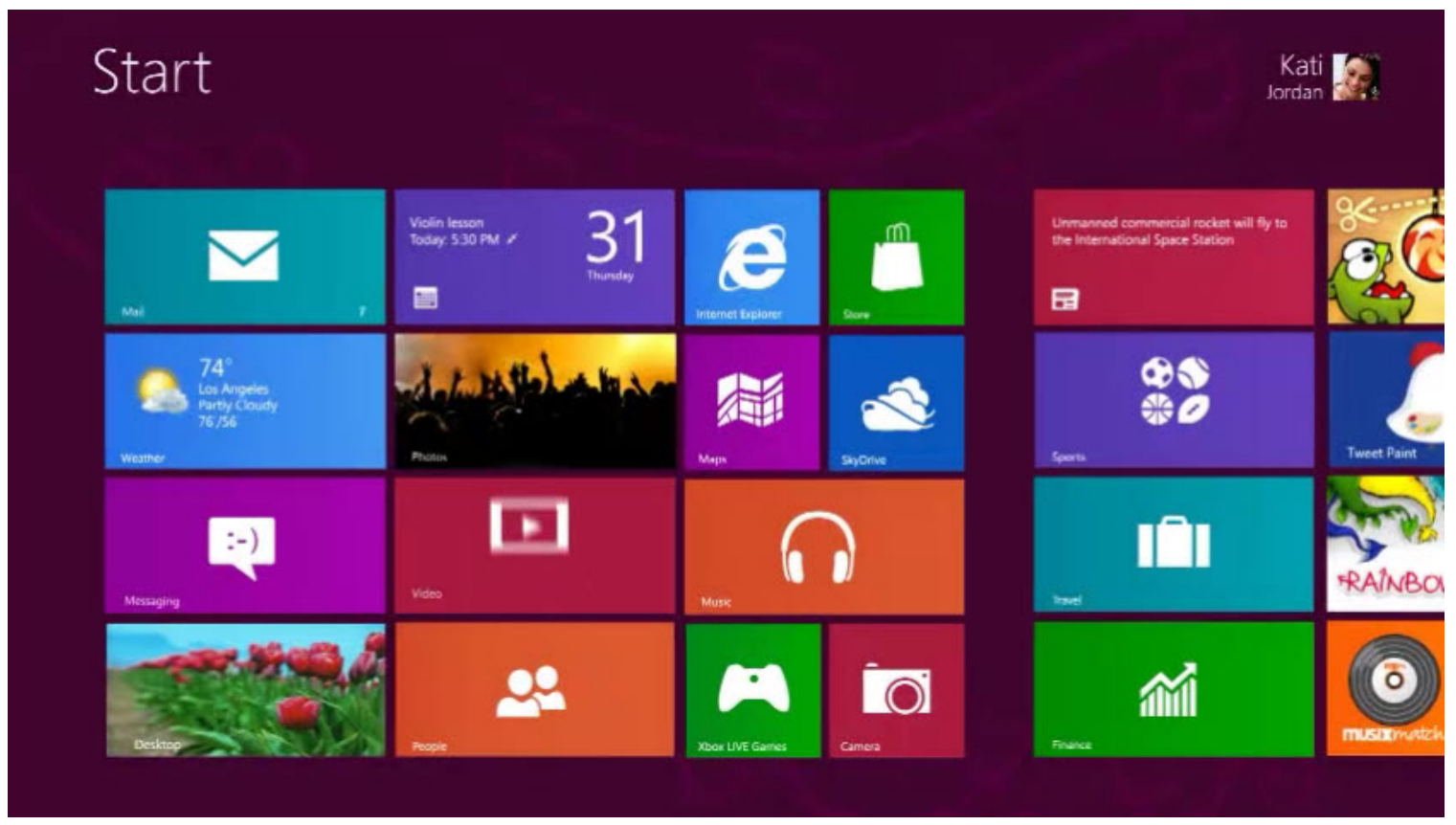

Figure 1. Windows 8 Start Screen (Source: Microsoft)

The other user interface, which loads on startup, represents the future direction of the operating system. Windows 8 is a bold departure from Windows 7, embodying a number of new design principles, such as rapid startup (about 10 seconds); a "clean," flat, 2-D appearance; a limited palette of bold colors; square or rectangular tiles replacing buttons; horizontal scrolling to move between programs or available selections; vertical scrolling to reveal program menus; and generally hiding much of the traditional user interface. Upon startup, Windows 8 presents the user with a Start Screen of tiles representing installed programs (ex., Internet Explorer) or services (ex., accessing the 7+ Desktop, weather reports, Windows Store). Tiles can be "live" (dynamically up- 
dating their contents) or static, colorful or drab (installed traditional applications have static, drab tiles). Users can organize tiles into groups or rearrange their placement to suit individual needs. Finger size does not impact selecting a tile or making scroll movements and usually does not affect menu selections within Windows 8 applications. Following the precedent of the online Apple Store, users will eventually acquire programs ("apps") designed for Windows 8 only by download from the Windows Store, with prices starting at US \$1.49. As per the Apple model, this method of distribution will give Microsoft far more control over the behavior of software loaded or updated on Windows 8 machines. Additionally, the company will also provide a way for schools, businesses, and governments to "side load" their own applications. Unless you need to do only some brief typing with the popup software keyboard, using a physical keyboard is a virtual necessity in either interface.

\section{Observations about Software Behavior}

The default method for logging into any version of Windows 8 or to access the Windows Store is to supply a MSN userid and password. Obtaining these is free, and they provide access to other Microsoft services, such as its SkyDrive cloud storage system.

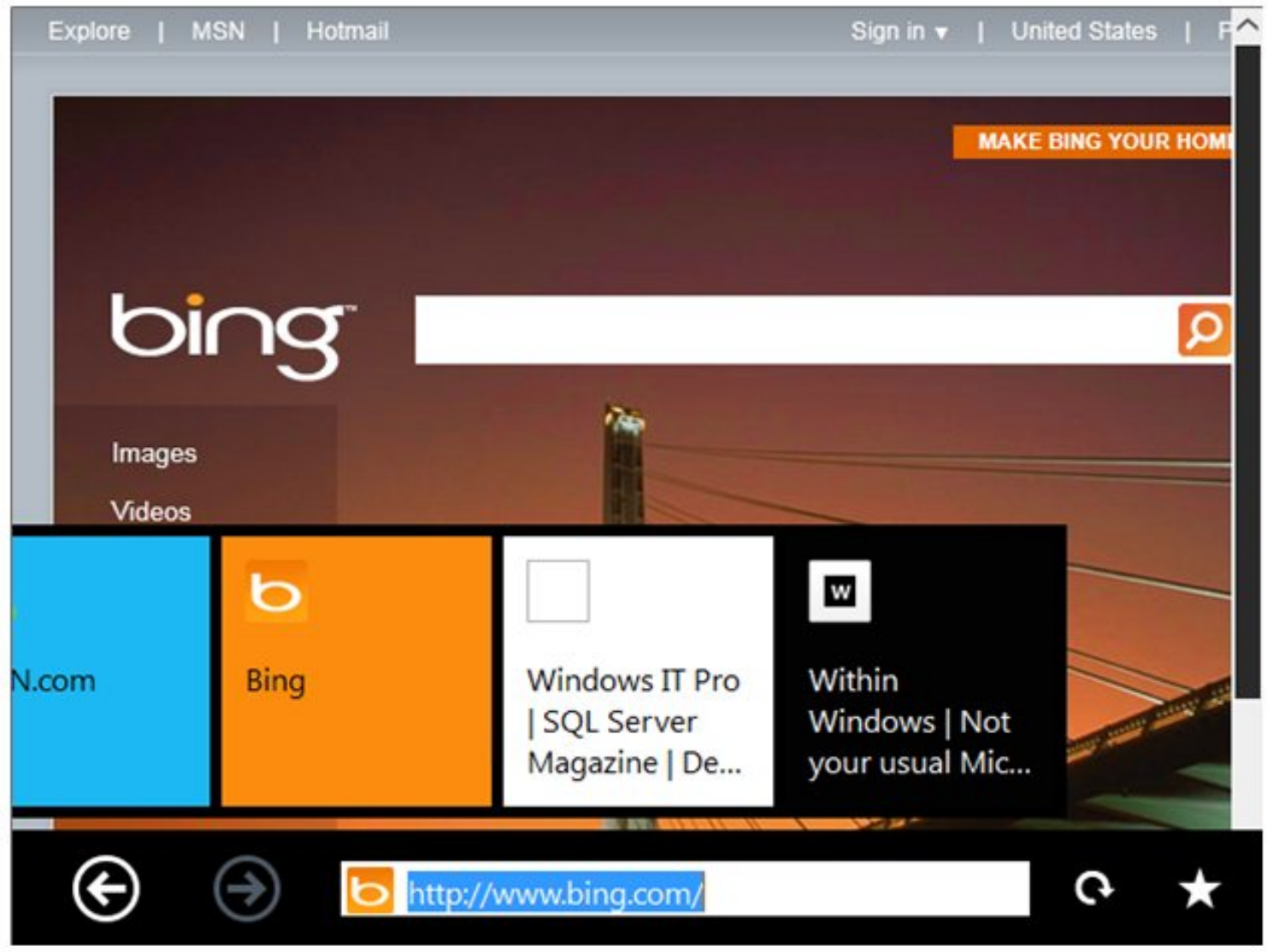

Figure 2. The Minimalist Windows 8 Version of Internet Explorer 10 (Source: Teknowlodgy.com)

Although the Windows Store is now starting to offer many apps, those programs -- like the operating system itself -- are early versions often incomplete or error-prone. Nevertheless, many are available for free and offer ways to become more familiar with the new interface. A great many of these apps are simply versions of traditional products or services rewritten for the Windows 8 
environment. Microsoft itself has done this with Internet Explorer 10, which comes in two versions for Windows $7+$ and 8 (Figure 2).

As noted earlier, pure Windows 8 (Win RT) will not run traditional Windows software (i.e., a program that would run under Windows 7 or earlier). With the other versions of Windows 8 , each traditional program appears as a static tile in the Start Menu that you touch to invoke Windows $7+$ and load the desired program. Alternatively, one can touch the Desktop tile to invoke $7+$ and load programs from there using a substitute Start Orb menu or by clicking on the appropriate desktop icon. Switching between 7+ and 8 is instantaneous. Microsoft says that any software designed for Windows 7 will run in Windows 7+, and the author's experience supports this contention.

The emphasis on screen simplification interface may be overdone, for example, making it harder to recognize desired icons or locate desired functionality. Microsoft has begun to redesign the user interfaces of its programs in this simplified style, as illustrated by the new versions of Visual Studio 2012, Expression Blend 5, and Office 2013. Use of color and 3-D icons has been largely suppressed. Earlier this year, the author had senior IT majors evaluate the beta versions of Visual Studio 2012 and Expression Blend 5. They found the products harder to use because the familiar visual landmarks present in earlier versions were more difficult to locate or missing. Another problem the students reported was that it was not always clear in software designed for Windows 8 if a given screen object was "hot" (i.e., represented or linked to a behavior).

\section{Recommendations for Educators}

Given what is known about Windows 8, there are at least six major recommendations ranked below by level of involvement with the product.

First, there is no compelling reason for schools or educators to upgrade to the new operating system. In the short term at least, Windows 8 (especially the RT version) will have its greatest impact on mobile devices, such as tablets, smartphones, and game consoles. Windows 8 does not have a "killer app" program which makes upgrading essential. Also, Windows 8 does not require a touch-screen monitor although it is more enjoyable with one. Microsoft will continue to offer products and services that run fine using Windows 7, including Office 2013 which is now available for download as a preview. Other vendors will behave similarly. Until that killer application appears, most PC users and schools will either stick with tried-and-true Windows 7 or run Windows 8 without a touch-screen interface.

Second, by October 2012 hardware manufacturers will start selling desktop, notebook, and tablet computers with Windows 8 pre-installed. Soon afterward, students will start appearing in class toting Windows 8 machines, most likely notebook computers with touch-screens. This will certainly be the case where schools require their students to own a PC and bring it to class. This is not cause for alarm. Any Windows $8 \mathrm{PC}$ will install and run traditional Windows software using the Windows 7+ interface. Minimally, schools and educators will need to know how to help students switch to Windows 7+, and what to do in Windows 8 to access the features previously exposed by the now-missing Start Orb, such as connecting to a printer.

Third, if you teach Windows-based software in your classes, for example Microsoft Office, students bringing Windows 8 computers to class or using them at home can raise more problems. Just as some vendors redesigned their programs to include task ribbons following the introduction of Microsoft Office 2007, you should expect some vendors to redesign their interfaces using Windows 8 principles (ex., flat look, less color). When this occurs, educators will at least need to update the illustrations they use and may have to devote more instruction time to mastering the redesigned interface. 
A far more significant educational challenge will arise from companies offering dual versions, 7+ and 8, of the same program. Microsoft has already done this with Internet Explorer 10 and, while the 7+ interface remains traditional, the 8 interface is very different and minimalist. All Windows 8 editions except WinRT install both versions. Schools and educators will have to support both and, where applicable, decide which version to teach in the classroom. Clearly, with this level of involvement, educators themselves will need considerable access to PCs running Windows 8.

Fourth, if you teach Windows-based computer programming, then you will need still more preparation, especially if you want students to write programs for the new interface. Windows 8 supports applications built using Silverlight (XAML) for the user interface and Visual Basic, C\#, C, or C++ for the "code-behind." However, the real emphasis now is using HTML5 and CSS3 for the interface and JavaScript for the code-behind. This push is industry-wide, from Android to Windows, and is all the more interesting because there are no official standards yet for either HTML5 or CSS3. For this level of involvement you will need Windows 8 installed on a PC that you use daily, along with Visual Studio 2012 and Expression Blend 5, which offer the tools needed to write apps for Windows 8 . One way to provide this environment to an entire class is to offer it on a virtual machine (VM) deployable in a lab or on a student's PC. This method keeps the original computing environment in place and gives better control over software behavior.

Fifth, Windows 8 could significantly change how people use mobile devices, especially tablets. Historically, people have used tablets primarily for consuming information downloaded from, or generated by, the Internet. Examples include reading eBooks, watching videos, monitoring weather or financial activity, and playing games. Using tablets for creating information has largely been limited to note taking, photography or videography, and social networking. The scarcity of tablet applications for creating and editing the kinds of information organizations use is a major reason why businesses have been slow to adopt tablet computing. Users of Windows 8 tablets, however, will not have this problem because the operating system will run the Windows 7 programs businesses already use. Combining business productivity tools with the convenience of tablet computing may be a game changer for many companies. Going forward, therefore, schools and teachers will have to decide if Windows 8 tablet computing has a role to play in the classroom and, if so, how to introduce and manage it.

Lastly, the immediate future of the Windows 8 is tied to its use on non-traditional computing devices, especially tablets. Microsoft realizes this. The RT version of Windows 8 runs only on the energy-efficient ARM chips found on many tablets, mobile phones, and other portable devices. Microsoft will launch its own brand of tablet PCs, called Surface, later this year with two models, one ARM-based and one Intel-based. Look for innovative applications which take advantage of Windows 8 features to first appear on tablets and mobile phones, before migrating to notebooks or desktops. The Angry Birds phenomenon, which started on Apple iPhones and iPod Touch, is an example of this.

\section{Conclusion}

If your current computing equipment can run Windows 7 , it will run Windows 8 . There is no touch-screen "killer app" available for Windows 8 that compels adoption of the operating system, so schools can put off that decision. For at least the next two years the bulk of applications running on Windows 8 will be mouse-driven, "legacy" (Windows 7 or even XP) programs. On the other hand, that very capability to run legacy software means that Windows 8 tablets and other mobile devices will be able to support a wide range of information creation activities, instead of mostly being appliances for information-consumption. It is likely that the development of 'pure' Windows 8 applications for tablet use will drive the future of this operating system. 


\section{Biography}

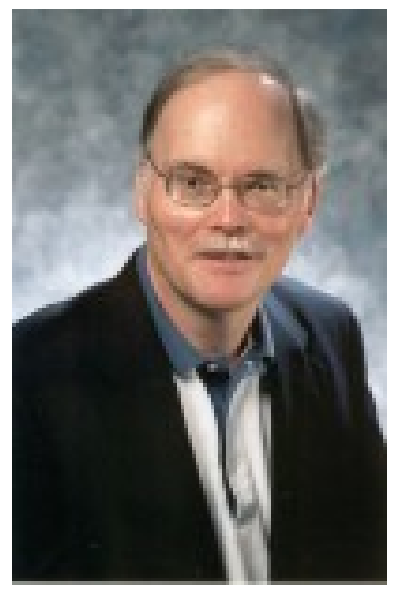

Dr. Richard Vedder is a Professor of Information Technology with the ITDS Department at the University of North Texas. His research interests include evaluation of emerging information technologies for business use. 